\title{
Oxidative Stress, Chromatin Remodeling and Gene Transcription in Inflammation and Chronic Lung Diseases
}

\author{
Irfan Rahman* \\ Respiratory Medicine, ELEGI Laboratory, MRC Centre for Inflammation Research, University of Edinburgh, Edinburgh, UK
}

Received 28 October 2002

Inflammatory lung diseases are characterized by chronic inflammation and oxidant/antioxidant imbalance. The sources of the increased oxidative stress in patients with chronic inflammatory lung diseases such as asthma and chronic obstructive pulmonary disease (COPD) derive from the increased burden of inhaled oxidants, and from the increased amounts of reactive oxygen species (ROS) generated by several inflammatory, immune and various structural cells of the airways. Increased levels of ROS produced in the airways is reflected by increased markers of oxidative stress in the airspaces, sputum, breath, lungs and blood in patients with lung diseases. ROS, either directly or via the formation of lipid peroxidation products such as 4-hydroxy-2-nonenal may play a role in enhancing the inflammation through the activation of stress kinases (JNK, MAPK, p38) and redox sensitive transcription factors such as NF- $\mathrm{kB}$ and AP-1. Recent evidences have indicated that oxidative stress and pro-inflammatory mediators can alter nuclear histone acetylation/ deacetylation allowing access for transcription factor DNA binding leading to enhanced pro-inflammatory gene expression in various lung cells. Understanding of the mechanisms of redox signaling, NF-KB/AP-1 regulation, the balance between histone acetylation and deacetylation and the release and expression of pro- and antiinflammatory mediators may lead to the development of novel therapies based on the pharmacological manipulation of antioxidants in lung inflammation and injury. Antioxidants that have effective wide spectrum activity and good bioavailability, thiols or molecules which have dual antioxidant and anti-inflammatory activity, may be potential therapeutic agents which not only protect against the direct injurious effects of oxidants, but may fundamentally alter the underlying inflammatory processes which play an important role in the pathogenesis of chronic inflammatory lung diseases.

*To whom correspondence should be addressed.

Tel: 44-131-651-3013; Fax: 44-131-650-1558

E-mail: Irfan.Rahman@ed.ac.uk
Keywords: AP-1, Chronic obstructive pulmonary disease, Cigarette smoke, Deacetylases, Histone acetylation, NF- $\kappa \mathrm{B}$, Reactive oxygen species, Lungs

\section{Introduction}

Oxidative stress has been implicated in the pathogenesis of several inflammatory lung disorders. Reactive oxygen species (ROS) such as superoxide anion $\left(\mathrm{O}_{2}{ }^{-}\right)$and hydroxyl radical $\left({ }^{\circ} \mathrm{OH}\right)$ are unstable molecules with unpaired electrons, capable of initiating oxidation. Biological systems are continuously exposed to oxidants either generated endogenously by metabolic reactions (e.g., from mitochondrial electron transport during respiration, during activation of phagocytes) or exogenously (such as air pollutants or cigarette smoke). The lung exists in a high-oxygen environment and, together with its large surface area and blood supply, is susceptible to injury mediated by ROS. Increased ROS production has been directly linked to oxidation of proteins, DNA, and lipids which may cause direct lung injury or induce a variety of cellular responses through the generation of secondary metabolic reactive species. ROS may alter remodeling of extracellular matrix, apoptosis and mitochondrial respiration, cell proliferation, maintenance of surfactant and the antiprotease screen, effective alveolar repair response and immune modulation in the lung (Rahman and MacNee 1999, 2000b). Furthermore, increased levels of ROS have been implicated in initiating the lung inflammatory response through the activation of transcription factors such as nuclear factor-kappaB (NF- $\kappa \mathrm{B})$ and activator protein-1 (AP-1), signal transduction, chromatin remodeling (histone acetylation/ deacetylation) and gene expression of pro-inflammatory mediators (Rahman and MacNee 1998). It is proposed that ROS produced by phagocytes that have been recruited to sites of inflammation, are a major cause of the cell and tissue damage associated with many chronic inflammatory lung diseases such as asthma, chronic obstructive pulmonary disease (COPD), idiopathic pulmonary fibrosis (IPF) and 
adult respiratory distress syndrome (ARDS) (Rahman and MacNee 1996, 1999, 2000a). All these diseases involve the recruitment of immune and inflammatory cells to the lungs. These cells are activated and produce mediators of inflammation including reactive oxygen species (ROS) and cytokines, such as the pro-inflammatory cytokine tumour necrosis factor- $\alpha$ (TNF- $\alpha)$.

This review describes the evidence for the role of ROS in the pathogenesis of chronic inflammatory lung diseases, discuss the ROS-mediated molecular mechanisms (cell signaling, chromatin remodeling and gene expression). Understanding of the molecular mechanisms of ROSmediated cell signaling pathways would provide information for development of novel antioxidant therapeutic targets in inflammation and injury.

\section{Cell-derived ROS}

A common feature of all inflammatory lung diseases is involvement of an inflammatory-immune response, characterised by activation of epithelial cells, and resident macrophages, and the recruitment and activation of neutrophils, eosinophils, monocytes, and lymphocytes. Inflammatory cells once recruited in the airspace become activated and generate ROS in response to a sufficient level of a secretagogue stimulus (threshold concentration). The activation of macrophages, neutrophils and eosinophils generates $\mathrm{O}_{2}{ }^{--}$, which is rapidly converted to $\mathrm{H}_{2} \mathrm{O}_{2}$ by superoxide dismutase (SOD), and ${ }^{\circ} \mathrm{OH}$, formed nonenzymatically in the presence of $\mathrm{Fe}^{2+}$ as a secondary reaction. ROS can also be generated intracellularly from several sources such as mitochondrial respiration, the NADPH oxidase system and xanthine/xanthine oxidase. However, the primary ROS-generating enzyme is NADPH oxidase, a complex enzyme system that is present in phagocytes and epithelial cells.

Several transition metal salts react with $\mathrm{H}_{2} \mathrm{O}_{2}$ to form ${ }^{\circ} \mathrm{OH}$. Most studies have focused on iron for the generation of ${ }^{\circ} \mathrm{OH}$ in vivo. Iron is a critical element in many oxidative reactions. Free iron in the ferrous form catalyses the Fenton reaction and the superoxide driven Haber-Weiss reaction, which generate the $\mathrm{OH}$, a ROS which damages tissues, particularly to cell membranes by lipid peroxidation. ROS, may also be released by lung epithelial cells (Rochelle et al., 1998) and also stimulate inflammatory cells directly thereby, amplifying lung inflammatory and oxidant events. ROS interact with a variety of molecules and donate electrons in biological systems. Reactive oxygen species also act on certain amino acids in proteins (e.g. enzymes, kinases) such as methionine, tyrosine and cysteine, profoundly altering the function of these proteins in inflammatory lung diseases.

\section{Inhaled Oxidants and Cigarette Smoke}

Cigarette smoking, inhalation of airborne pollutants, either oxidant gases (such as ozone, nitrogen dioxide $\mathrm{NO}_{2}$, sulphur dioxide $\mathrm{SO}_{2}$ ) or particulate matters results in direct lung damage as well as in the activation of lung inflammatory responses. Cigarette smoke is a complex mixture of over 4,700 chemical compounds, including high concentrations of oxidants $10^{14}$ per puff (Church and Pryor 1985). Short-lived oxidants such as $\mathrm{O}_{2}{ }^{\cdot-}$ and nitric oxide (NO) are predominantly found in the gas-phase. $\mathrm{NO}$ and $\mathrm{O}_{2}{ }^{--}$immediately react to form highly reactive peroxynitrite $\left(\mathrm{ONOO}^{-}\right)$. The radicals in the tar phase of cigarette smoke are organic in nature, such as long-lived semiquinone radicals which can react with $\mathrm{O}_{2}{ }^{-}$to form ${ }^{\circ} \mathrm{OH}$ and $\mathrm{H}_{2} \mathrm{O}_{2}$ (Pryor and Stone, 1993). This aqueous phase of the cigarette smoke condensate may undergo redox recycling for a considerable period of time in epithelial lining fluid (ELF) of smokers (Zang et al., 1995). The tar phase is also an effective metal chelator and can bind iron to produce tar-semiquinone + tar- $\mathrm{Fe}^{2+}$, which can generate $\mathrm{H}_{2} \mathrm{O}_{2}$ continuously. Furthermore, since both cigarette tar and lung epithelial lining fluid contain metal ions, such as iron, Fenton reaction will result in the production of the ${ }^{\circ} \mathrm{OH}$ which is a highly reactive and potent ROS.

\section{ROS and Membrane Lipid Peroxidation}

Reactive oxygen species such as $\mathrm{O}_{2}{ }^{-}$and ${ }^{\circ} \mathrm{OH}$, generated and released by activated immune and inflammatory cells are highly reactive, and when generated close to cell membranes oxidise membrane phospholipids (lipid peroxidation) which may initiate a chain reaction. Thus, a single ${ }^{\circ} \mathrm{OH}$ can result in the formation of many molecules of lipid hydroperoxides in the cell membrane. The peroxidative breakdown of polyunsaturated fatty acids impair membrane function and inactivate membrane-bound receptors and enzymes, increase tissue permeability which have been implicated in the pathogenesis of many forms of lung injury. There is increasing evidence that aldehydes, generated endogenously during the process of lipid peroxidation, are involved in many of the pathophysiological effects associated with oxidative stress in cells and tissues. Compared with free radicals, lipid peroxidation aldehydes are generally stable, can diffuse within, or even escape from the cell and attack targets far from the site of the original free radical event. In addition to their cytotoxic properties, lipid peroxides are increasingly recognised as being important in signal transduction for a number of important events in the inflammatory response (Fig. 1).

Isoprostanes (a member of $\mathrm{F}_{2}$-isoprostane family) are ROS catalysed isomers and stable end-products of non-enzymatic 


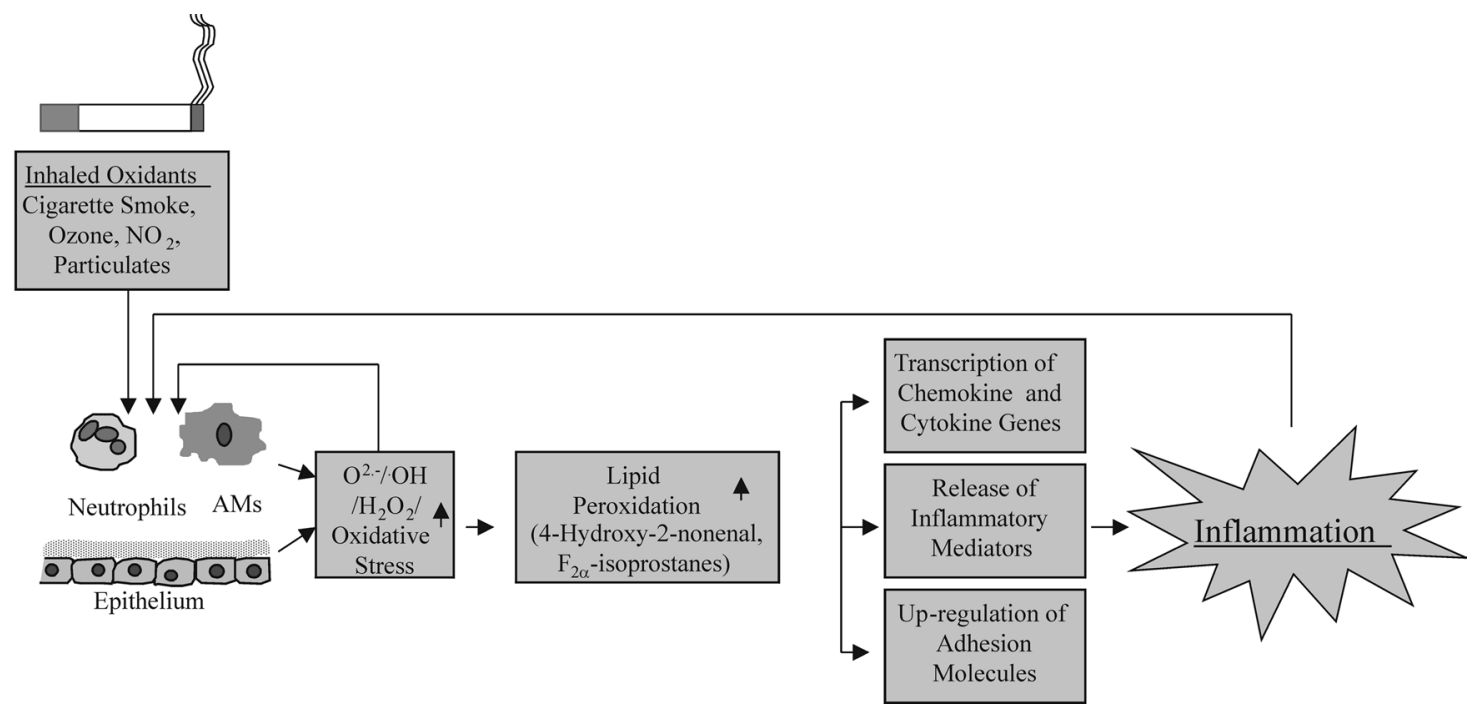

Fig. 1. Mechanisms of ROS-mediated lung inflammation. Inflammatory response is mediated by oxidants either inhaled and/or released by the activated neutrophils, alveolar macrophages, eosinophils and epithelial cells leading to production of ROS and membrane lipid peroxidation. Activation of transcription of the pro-inflammatory cytokine and chemokine genes, up-regulation of adhesion molecules and increased release of pro-inflammatory mediators which is involved in the inflammatory responses in patients with chronic inflammatory diseases.

lipid peroxidation of arachidonic acid. $F_{2}$-isoprostane is a potent smooth muscle cell constrictor and a mitogen and modulates platelet as well as other cell functions in vitro via membrane receptors (thromboxane $\mathrm{A}_{2}$ ) for prostaglandins (Morrow and Roberts, 1997). 4-hydroxy-2-nonenal (4-HNE), a highly reactive diffusible end product of lipid peroxidation, is known to induce/regulate various cellular events in particular proliferation, apoptosis and activation of signaling pathways (Parola et al., 1999; Uchida et al., 1999). 4-HNE has a high affinity towards cysteine, histidine and lysine residues, alters protein function and forms direct proteinadducts. Many of the effects of ROS in airways may be mediated by the secondary release of inflammatory lipid mediators such as 4-HNE. Inhibition of lipid peroxidation, specifically the pathways leading to the production of 4-HNE and $\mathrm{F}_{2}$-isoprostane, may be used as targets for antioxidant therapy in inflammation and injury in patients with chronic lung diseases such as asthma, COPD, IPF and ARDS.

\section{ROS-mediated DNA Damage}

Cigarette smoke has been shown to induce sister chromatid exchanges, micronuclei, cell transformations in vitro and tumor induction in vivo (Perera et al., 1987). Cigarette smokederived free radicals/oxidants have been shown to damage DNA, e.g. incubation of bacteriophage DNA with buffered aqcueous extracts of cigarette tar results in a dose-dependent production of single-strand breaks in DNA (Boris 1987). Cigarette smoke condensate (CSC)-mediated DNA strand break is protected by ${ }^{\circ} \mathrm{OH}$ radical scavengers suggesting that the ${ }^{\circ} \mathrm{OH}$ is responsible for DNA nicks caused by cigarette smoke condensate (Pryor, 1992). It has been shown that cigarette smoke tar radical (quinone) complexes with or becomes bonded to the DNA suggesting that CSC acts as a site- or base-sequence-specific DNA cleavage agent. Bermudez et al have shown that tar component in sidestream cigarette smoke produces DNA nicks which was prevented by glutathione in rat alveolar macrophages (Bermedez et al., 1994). Similarly Izzotti et al have shown that $\mathrm{N}$-acetylcysteine inhibited the carcinogen-DNA adducts in the tracheal epithelium of rats exposed to cigarette smoke (Izzotti et al., 1995).

Chronic cigarette smoking increases the number of neutrophils in lung fluid and organic compounds such as catechol and hydroquinone which may activate these cells to produce increased amount of ROS. Leanderson and Tagesson have reported that neutrophils can cause oxidative DNA damage (formation of 7-hydro-8-oxo-2 deoxyguanosine (8oxodG) in alveolar epithelial cells through the generation of ROS. Similarly, Asami et al have demonstrated increased levels of 8-hydroxyguanine in leukocytes obtained from smokers as compared to nonsmokers (Asam et al., 1996). Furthermore, increased levels of cigarette smoke-mediated carcinogen-DNA have been demonstrated in lung tissue of smokers, which may be associated with increased iron burden in lower respiratory tract (Thompson et al., 1991; Philips et al., 1998). This suggests that the recruitment of inflammatory cells may cause oxidative DNA damage in lung cells which may be a contributing factor in the pathogenesis of lung cancer. 


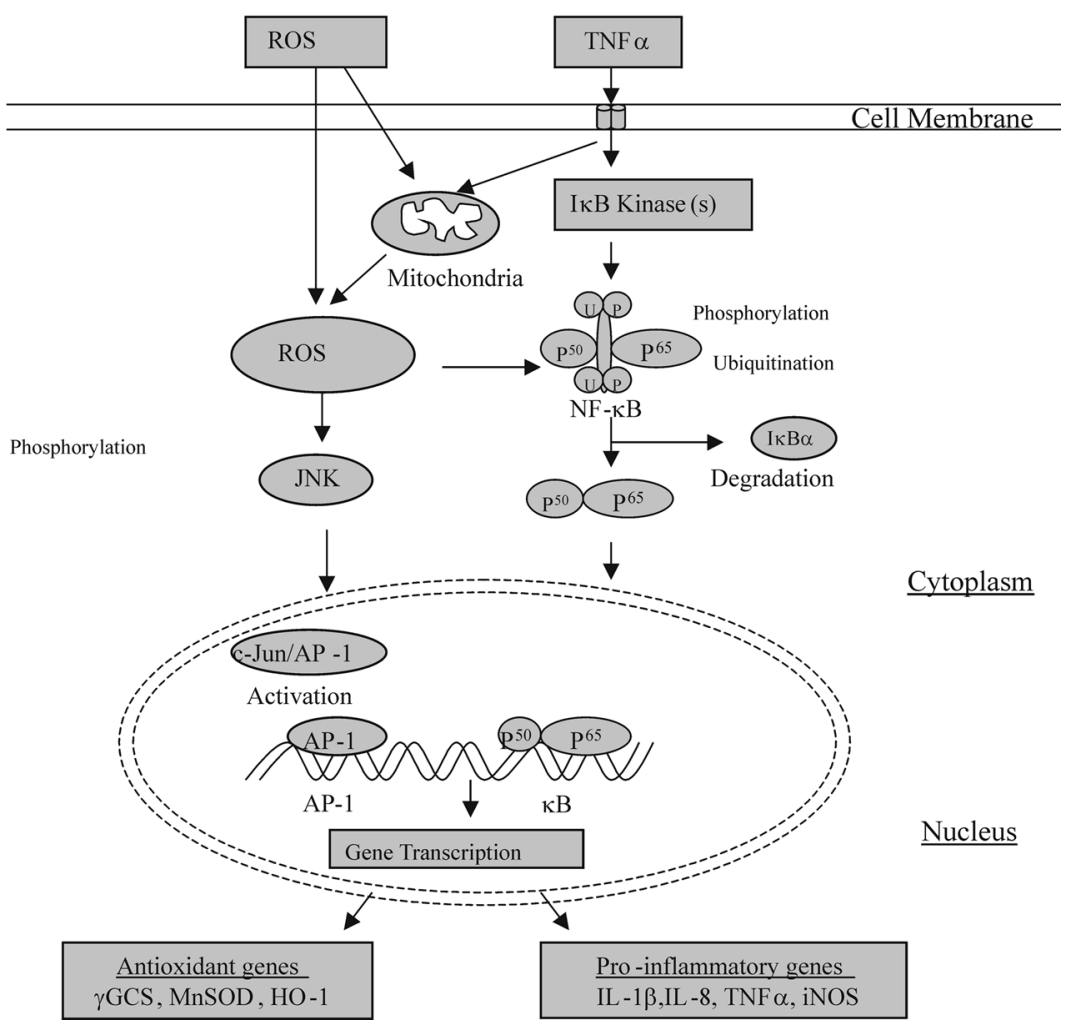

Fig. 2. Model for the ROS-mediated mechanism of NF- $\kappa B$ and AP-1 activation leading to the gene transcription. ROS directly or directly (its generation via mitochondria) are involved in the activation of NF- $\kappa \mathrm{B}$ and AP-1. Activation of NF- $\kappa \mathrm{B}$ involves the phosphorylation, ubiquitination, and subsequent proteolytic degradation of the inhibitory protein IKB. Free NF- $\kappa \mathrm{B}$ then translocates into the nucleus and binds with its consensus sites. Similarly, AP-1 either c-Jun/c-Jun (homodimer) or c-Fos/c-Jun (heterodimer) is activated by the phorphorylation of JNK pathway leading to the activation AP-1 and binds with its TRE consensus regions. Activation of NF- $\kappa \mathrm{B} /$ AP-1 leads to the co-ordinate expression of antioxidant protective and pro-inflammatory genes.

\section{Role of ROS in Signal Transduction}

The expression of inflammatory mediators can be regulated by the activation of redox-sensitive transcription factors AP-1 and NF- $\kappa \mathrm{B}$ stimulated in response to ROS and TNF- $\alpha$ (Rahman and MacNee, 1998; Rahman et al., 2001c) (Fig. 2). In addition to ROS, cellular redox status, particularly intracellular thiol status can be directly involved in the activation of AP-1 and NF- $\kappa$ B, signal transduction and gene expression involved in cellular pathophysiologic activities. Both environmental or inflammatory cell-derived ROS can lead to the activation and phosphorylation of the mitogen activated protein kinase (MAPK) family, including extracellular signal regulated kinase (ERK), c-Jun N-terminal kinase (JNK), p38 kinase, and the phosphoinositide 3 signaling protein (PI-3K) via sensitive cysteine rich domains, sphingomyelinase-ceramide pathway, leading to increased gene transcription (Thannickal and Fanburg, 2000). Activation of members of the MAPK family leads to the transactivation of transcription factors such as c-Jun, activating factor-2 (ATF2), cyclic AMP response element binding proteins (CREB)-binding protein (CBP) and Elk-1 (Adler et al., 1999). This eventually results in chromatin remodeling and expression of genes regulating a battery of distinct proinflammatory and antioxidant genes involved in several cellular events including apoptosis, proliferation, transformation and differentiation.

The exact intracellular molecular mechanism of ROS action has not been completely characterised. Redox sensitive molecular targets usually contain highly conserved cysteine residues, and their oxidation, nitration, and formation of disulfide links are crucial events in oxidant/redox signaling. It is hypothesized that oxidation of those sulfide groups in signaling proteins causes structural modifications, resulting in the exposure of active sites and protein activation. Such molecular targets include transcription factors (NF- $\mathrm{KB}$ and AP-1), signaling molecules such as ras/rac or JNK, protein tyrosine phosphatases and $\mathrm{p} 21^{\text {ras }}$. Thiol molecules such as intracellular glutathione (GSH) and thioredoxin are of central therapeutic importance in the regulated control of such redox signaling pathways, by reducing disulfide bridges or oxidised cysteine residues (Rahman and MacNee, 2000a).

Recent studies have shown that in response to tumour necrosis factor (TNF $\alpha$ ) and lipopolysaccharide (LPS), which are relevant stimuli for the inflammatory response in chronic inflammatory lung diseases, airway epithelial cells can 


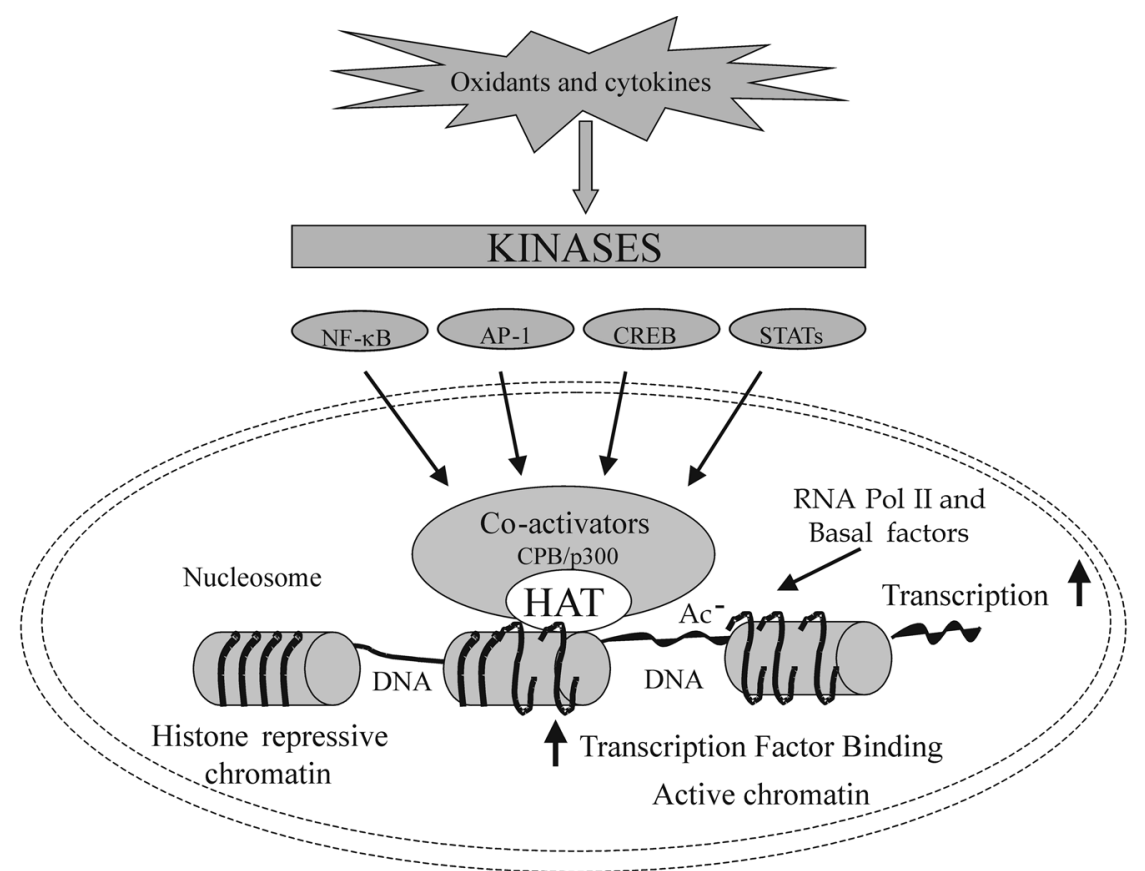

Fig. 3. Co-activator transcriptional complex. The instrinsic HAT activity of master co-activator $\mathrm{CBP} / \mathrm{p} 300$ and other transcription factors/ co-activators acetylate lysine moiety of histone proteins which leads to the loosening of chromatin (gene transcription).

concurrently produce increased amounts of intracellular ROS. This intracellular production of oxidants and the subsequent changes in intracellular GSH redox status is important in the molecular events controlling the expression of genes for inflammatory mediators. The signaling pathways and activation of transcription factors in response to ROS are subject of rigorous investigation.

\section{Role of ROS in Chromatin Remodeling and Gene Transcription}

Chromatin remodeling Gene transactivation is controlled by multimeric complexes of transcriptional coactivators and co-repressors which bind to consensus sites within gene promoters and regulate transcription. Many factors, including specific DNA sequences, histones, non-histone chromosomal proteins, transcriptional activators/repressors and the transcription machinery are all necessary for the establishment of an active transcription complex. Condensation of eukaryotic DNA in chromatin suppresses gene activity through the coiling of DNA on the surface of the nucleosome core and the folding of nucleosome assemblies, thus decreasing the accessibility to the transcriptional apparatus (Wu, 1997). The basic unit of chromatin, the nucleosome, consists of 146 base pairs of DNA wrapped around two subunits each of highly conserved core histones H2A, H2B, $\mathrm{H} 4$ and H4. Tightly bound DNA around a nucleosome core (histone proteins $\mathrm{H} 2 \mathrm{~A}, \mathrm{H} 2 \mathrm{~B}, \mathrm{H} 3$ and $\mathrm{H} 4$ ), suppresses gene transcription by decreasing the accessibility to transcription factors, such as NF-kB and AP-1 to the transcriptional complex. Acetylation of lysine residues in the $\mathrm{N}$-terminal tails of the core histone proteins results in uncoiling of the DNA, allowing increased accessibility for transcription factor binding. Acetylation of lysine (K) residues on histone 4 (K5, $\mathrm{K} 8, \mathrm{~K} 12, \mathrm{~K} 16$ ) is thought to be directly related in the regulation of gene transcription (Imhof and Wolffe, 1998). However, core histones may also be modified by phosphorylation, methylation, ADP-ribosylation, or ubiquitination of a specific amino acid residue (Davie and Spencer, 2001). Histone acetylation is reversible and is regulated by a group of acetyltransferases (HATs) which promote acetylation, and deacetylases (HDACs) which promote deacetylation.

The nuclear receptor coactivators, steroid receptor coactivator 1 (SRC-1), cyclic AMP response element binding (CREB)-binding protein (CBP)/adenoviral protein E1A (p300) protein, CBP/p300 associated factor (P/CAF), and Activator Transcription Factor-2 (ATF-2), all possess intrinsic HAT activity (Ogryzko et al., 1996; Kawasaki et al., 2000; Pham et al., 2000). Of these, CBP/p300 and ATF-2, which are regulated by MAP kinase pathways, are vital for the coactivation of several transcription factors including NF- $\mathrm{\kappa B}$ and AP-1 in the transcription machinery (Thomson et al., 1999). These activation complexes act with RNA polymerase II to initiate transcription (Fig. 3). Thus, it is likely that acetylation of $\mathrm{H} 3 / \mathrm{H} 4$ via $\mathrm{CBP} / \mathrm{p} 300$ and/or ATF-2 has a significant role in the activation of NF- $\mathrm{KB} / \mathrm{AP}-1$-mediated gene expression for pro-inflammatory mediators, although the precise molecular mechanisms are still not fully understood. 


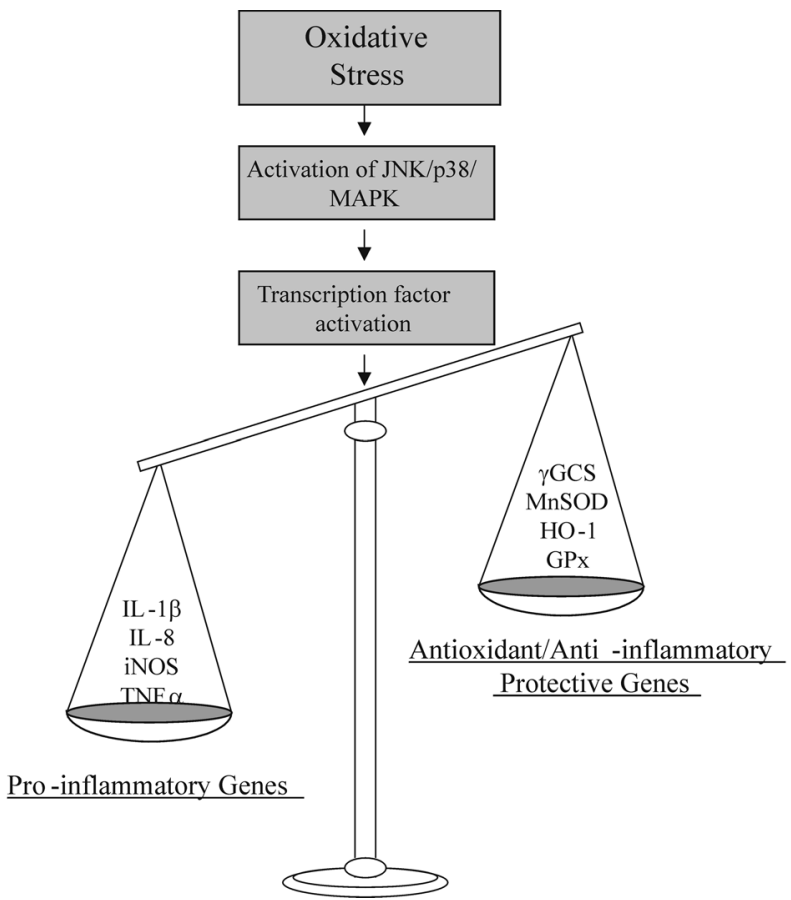

Fig. 4. Activation of transcription factors NF- $\mathrm{KB}$ and AP-1 by oxidants and/or pro inflammatory cytokines activate MAP kinase pathways that lead to the induction of both pro-inflammatory and anti-inflammatory/antioxidant genes in lung cells. In inflammation, the balance appears to be tipped in favour of increased pro-inflammatory mediators, either because of release of inflammatory mediators, or amplification of the pro-inflammatory effects. Induction of antioxidant protective genes may be a delayed response and declined sharply or overtaken by pro-inflammatory effects.

Disruption of the nucleosome or DNA unwinding caused by deacetylation inhibitors facilitates AP-1 binding ( $\mathrm{Ng}$ et al., 1997). It has been suggested that oxidant generating systems and proinflammatory mediators influence histone acetylation/ phosphorylation via a mechanism dependent on the activation of the MAPK pathway (Bohm et al., 1997; Tikoo et al., 2001; Miyata et al., 2002). Recent evidences have shown that oxidative stress induced by $\mathrm{H}_{2} \mathrm{O}_{2}$ and TNF- $\alpha$ increases the activation of AP-1 and NF- $\mathrm{KB}$, and may regulate chromatin remodeling leading to IL-8 expression (Rahman et al., 2001b). This may have role in cell proliferation, apoptosis and imbalance in gene transcription for pro-inflammatory mediators and antioxidant protective genes.

The family of HDAC enzymes consists of ten distinct deacetylases. HDACs remove the acetyl moieties from the $\varepsilon$ acetamido groups of lysine residues of histones (restoration of positive charges) causing rewinding/condensation of DNA associated with displacement of transcription factors from their cognitive DNA binding sites leading to silencing of gene transcription. HDACs associate in multimeric complexes which serve to direct these proteins to specific promoter sites. HDACs represent a super family of molecules sharing a 390amino acid region of homology known as the deacetylase core (Finnin et al., 1999). HDACs are found complexed to corepressor molecules like Sin3, N-CoR, and SMRT. Recently, the role of HDACs (1 and 2) has been shown in the regulation of cell proliferation and corticosteroid-mediated inhibition of pro-inflammatory mediators (Sambucetti et al., 1999; Ito et al., 2000). Several distinct HDACs are now recognized, and these are differentially expressed and regulated in different cell types. This may contribute to the responsiveness to corticosteroids between different stimuli, genes and cell types.

Gene transcription Inflammatory mediators play a crucial role in chronic inflammatory processes and appear to determine the nature of the inflammatory response by directing the selective recruitment and activation of inflammatory cells and their perpetuation within the lungs. In in vitro studies, using macrophage, alveolar, and bronchial epithelial cells, ROS have been shown to cause increased gene expression of inflammatory mediators such as IL-1 and TNF$\alpha$. Direct or indirect oxidant stress to the airway epithelium and alveolar macrophages may also generate cytokines such as TNF- $\alpha$ which in turn can activate airway epithelial cells to induce proinflammatory genes such as TNF- $\alpha$, IL-8, IL-1, inducible NO synthase, COX-2, ICAM-1, IL-6, MIP-1, GMCSF, stress response genes (HSP-27, 70, 90, HO-1) and antioxidant enzymes $(\gamma$-glutamylcysteine synthetase $\gamma$-GCS, MnSOD, thioredoxin). The genes for these inflammatory mediators are regulated by redox-sensitive transcription factors such as NF- $\mathrm{KB}$ and AP-1 (Fig. 4). 
An important effect of oxidative stress and inflammation is the upregulation of protective antioxidant genes. Among the antioxidant enzymes, GSH and its redox enzymes appear to have an important protective role in the airspaces and intracellularly in epithelial cells. Oxidative stress causes upregulation of $\gamma$-GCS, an important enzyme involved in the synthesis of GSH, as an adaptive mechanism against subsequent oxidative stress. Important protective antioxidant and stress response genes such as mRNA for MnSOD, $\gamma$-GCS, heme oxygenase-1 (HO-1), glutathione peroxidase, thioredoxin reductase and metallothionein are induced by various oxidative stresses including hyperoxia and inflammatory mediators such as TNF- $\alpha$ and lipopolysaccharide in lung cells.

Thus oxidative stress, including redox modulation, causes increased gene expression of both pro-inflammatory genes by oxidant-mediated activation of transcription factors such as $\mathrm{AP}-1$ and NF- $\mathrm{KB}$ and also activation of stress response protective genes such as $\gamma$-GCS-HS, HO- 1 and MnSOD in lungs. Both ROS, and redox modulation cause increased gene expression of both pro-inflammatory genes by ROS-mediated activation of redox-sensitive transcription factors and also activation of stress response and antioxidant protective genes in the lungs. A balance may therefore exist between pro- and anti-inflammatory gene expression and the levels of GSH in response to ROS and during inflammation, which may be critical to whether this leads to cell injury or protection against the injurious effects of inflammation.

\section{Smokers and Patients with Chronic Obstructive Pulmonary Disease}

Chronic Obstructive Pulmonary Disease (COPD) is a slowly progressive condition characterised by airflow limitation, which is largely irreversible. Airway inflammation in COPD, is characterized by premodinantly by neutrophils and macrophages. COPD is characterized by chronic inflammation of the respiratory tract, even in ex-smokers. The increased oxidant burden derives from the fact that cigarette smoke, contains an estimated $10^{14}$ oxidants per puff and many of these are relative long-lived such as tar-semiquinone which can generate ${ }^{\circ} \mathrm{OH}$ and hydrogen peroxide $\left(\mathrm{H}_{2} \mathrm{O}_{2}\right)$ by the Fenton reaction (Pryor and Stone, 1993; Zang et al., 1995). It is reported that more than $90 \%$ of patients with COPD are smokers, but not all smokers develop COPD (American Thoracic Society, 1995; British Thoracic Society, 1997). 15$20 \%$ of cigarette smokers appear to be susceptible to its effects and show a rapid decline in forced expiratory volume in one second $\left(\mathrm{FEV}_{1}\right)$ and develop the disease. The major risk factor for COPD is cigarette smoke, which is one of the most potent oxidants. Other factors that may exacerbate COPD, such as air pollutants, infections, and occupational dusts, are also potential oxidants. Thus, oxidants present in cigarette smoke and environmental pollutants may play an important role in the pathogenesis of COPD.

\section{ROS in Alveolar Space}

The ROS burden in the lungs is enhanced in smokers by the release of ROS from macrophages and neutrophils. Oxidants present in cigarette smoke can stimulate alveolar macrophages to produce ROS and to release a host of mediators, some of which attract neutrophils and other inflammatory cells into the lungs. Both neutrophils and macrophages, which are known to migrate in increased numbers into the lungs of cigarette smokers, compared with non-smokers can generate ROS via the NADPH oxidase complex system. Moreover, the lungs of smokers with airway obstruction have more neutrophils than smokers without airway obstruction (Bosken et al., 1992). Circulating neutrophils from cigarette smokers and patients with exacerbations of COPD release more $\mathrm{O}_{2}{ }^{--}$(Rahman et al., 1996b). Cigarette smoking is associated with increased content of MPO in neutrophils (Aaron et al., 2001), which is correlated with the degree of pulmonary dysfunction (Fiorini et al., 2000). MPO activity was also found to be correlated negatively with $\mathrm{FEV}_{1}$ in patients with COPD, suggesting that neutrophil MPO-mediated oxidative stress and inflammatory response play an important role in the pathogenesis of COPD (Gompertz et al., 2001).

\section{ROS in Blood}

The circulating neutrophil appears to be a critical cell in the pathogenesis of COPD. Previous epidemiological studies have shown a relationship between circulating neutrophil numbers and the $\mathrm{FEV}_{1}$ (Chan-Yeung et al., 1988). Moreover, a relationship has also been shown between the change in peripheral blood neutrophil count and the change in airflow limitation over time. Similarly, a correlation between $\mathrm{O}_{2}{ }^{--}$ release by peripheral blood neutrophils and bronchial hyperreactivity in patients with COPD has been shown, suggesting a role for systemic ROS in the pathogenesis of the airway abnormalities in COPD (Postma et al., 1988). Another study has shown a relationship between peripheral blood neutrophil luminol enhanced chemiluminescence, as a measure of the release of ROS and measurements of airflow limitation in young cigarette smokers (Richards et al., 1989).

Various studies have demonstrated increased production of $\mathrm{O}_{2}{ }^{--}$from peripheral blood neutrophils obtained from patients during acute exacerbations of COPD, which returned to normal when the patients were restudied when clinically stable (Rahman et al., 1997). Other studies have shown that circulating neutrophils from patients with COPD show upregulation of their surface adhesion molecules, which may also be an oxidant-mediated effect (Rahman et al., 1996b; Noguera et al., 1998). Activation may be even more pronounced in neutrophils which are sequestered in the pulmonary microcirculation in smokers and in patients with COPD, since neutrophils which are sequestered in the pulmonary microcirculation in animal models of lung 
inflammation release more ROS than circulating neutrophils (Brown et al., 1995). Thus neutrophils, which are sequestered in the pulmonary microcirculation may be a source of ROS, and may have a role in inducing endothelial adhesion molecule expression in COPD.

\section{Generation of ROS-mediated Lipid Peroxidation Products}

Isoprostanes are products of non-enzymatic lipid peroxidation and have therefore been used as markers of oxidative stress. The isoprostanes (members of $\mathrm{F}_{2}$-isoprostane), are ROS catalysed isomers of arachidonic acid and are stable lipid peroxidation products, which circulate in plasma and are excreted in the urine. The levels of lipid peroxides, such as 8isoprostane and the hydrocarbons ethane and pentane, are increased in exhaled air condensate in smokers and in patients with COPD (Montuschi et al., 2000; Paredi et al., 2000). Furthermore, the increased levels of these markers of lipid peroxidation products have been correlated with airway obstruction (decline in $\mathrm{FEV}_{1}$ ). We have recently shown that the plasma and BALF levels of F2-isoprostane were increased in smokers and patients with COPD. Furthermore, the level of F2-isoprostanes was more pronounced in plasma during exacerbations of COPD. Thus it indicates that there is increased lipid peroxidation in patients with COPD, implicating direct oxidative damage of epithelial cells and an enhanced airway inflammatory response. Lipid peroxidation may also have a role in the signaling events in the molecular mechanisms involved in the lung inflammation in COPD. However, it is not known whether the increased level of lipid peroxidation products found in these diseases are the result of primary lung-associated processes, such as alveolar macrophage activation, neutrophil activity, or caused by the ongoing lipid peroxidative chain reaction in the alveoli, parenchyma, or airways, which are induced by inhaled oxidants/cigarette smoke.

Indirect and non-specific measurements of lipid peroxidation products, such as thiobarbituric acid reactive substances (TBARS), have also been shown to be elevated in breath condensate and in lungs of patients with stable COPD (Morrison et al., 1999; Nowak et al., 1999). The levels of plasma lipid peroxides (TBARS) have been shown to be elevated in COPD and negatively correlated with the $\mathrm{FEV}_{1}$, suggesting that increased oxidative stress occur in patients with COPD (Rahman et al., 1996b). Thus the crude measurement of the levels of TBARS might not be a marker to discriminate between asthma and COPD. Oxidative stress, measured as lipid peroxidation products in plasma, has also been shown to correlate inversely with the \% predicted $\mathrm{FEV}_{1}$ in a population study (Britton et al., 1995). This indicates that in patients with COPD lipid peroxidation may play a role in the progression of the disease.

Specific end products of lipid peroxidation may be a good marker of COPD. 4-HNE is a highly reactive and specific diffusible end-product of lipid peroxidation. Our preliminary data indicate increased 4-HNE-modified protein levels in airway and alveolar epithelial cells, endothelial cells and neutrophils in subjects with airway obstruction compared to subjects without airway obstruction (Rahman et al., 2001a). This demonstrates not only the presence of 4-HNE but that 4HNE modifies proteins in lung cells to a greater extent in patients with COPD. The increased level of 4-HNE-adducts in alveolar epithelium, airway endothelium and neutrophils was inversely correlated with $\mathrm{FEV}_{1}$, suggesting a role for 4-HNE in the pathogenesis of COPD.

\section{Cigarette Smoke-mediated Lipid Peroxidation, Cell Signaling and Gene Transcription}

Lipid peroxidation products, in particular aldehydes, derived from cigarette smoke have been shown to act as a signal for activation of transcription factors and gene expression leading to inflammatory response. Cigarette smoke extract stimulates protein kinase $\mathrm{C}$, possibly by the formation of aldehydes/lipid peroxidation products in human bronchial epithelial cells (Wyatt et al., 1999). Cigarette smoke can activate epidermal growth factor (EGF) receptors by tyrosine phosphorylation, resulting in the induction of mucin synthesis in epithelial cells and in vivo in lungs (Takeyama et al., 2001). Levels of ras ${ }^{\mathrm{p} 21}$ oncoprotein were higher in plasma of patients with COPD, suggesting cytogenetic damage and abnormal signal transduction by smoking (Cebulska et al., 1999). In vitro experiments have demonstrated that cigarette smoke condensate induces a distinct pattern of stress response in cultured epithelial cells, which may be related to the reported pro-inflammatory activities of CSC (via the formation of ROS/lipid peroxidation products) in vitro and in vivo.

Oxidative stress has been implicated in the expression of both pro-inflammatory and protective antioxidant genes. The $c$-fos gene belongs to a family of growth and differentiationrelated immediate early genes, the expression of which generally represents the first measurable response to a variety of chemical and physical stimuli. Studies in various cell lines have shown enhanced gene expression of the $c$-fos in response to cigarette smoke (Muller, 1995). These effects of cigarette smoke can be mimicked by peroxynitrite and smoke-related aldehydes (4-HNE/ $\mathrm{F}_{2}$-isoprostanes, acrolein, acetaldehyde) in concentrations that are present in cigarette (Muller et al., 1997). AP-1 (c-Fos/c-Jun) DNA binding is increased in epithelial and endothelial cells in response to cigarette smoke condensate (CSC), whereas CSC causes an initial decrease in the DNA binding of NF-kB following by a subsequent 2-fold increase in DNA binding (Muller and Gebel, 1998; Freed et al., 2001; Gebel and Muller, 2001). This is associated with the lack of phosphorylation and degradation of Ikappa B- $\alpha$ in CSC treated cells. NF- $\kappa \mathrm{B}$ and $\mathrm{AP}-1$, and its components are increased in lungs of smokers and patients with COPD. 
Recently, Mochida-Nishimura et al. have demonstrated that increased activation of NF- $\mathrm{KB}$ and MAP kinase pathways by LPS occurs in BAL cells from smokers than non-smokers (Mochida-Nishimura et al., 2001). They found that activation of p38 was more rapid in BAL cells from smokers compared to non-smokers. However, Chang et al. have shown that MAP kinases (MEK1 and ERK2) were increased without any change in the levels of p38 in terminal bronchioles in the lungs of rats exposed to cigarette smoke (Chang et al., 2001). Furthermore, recent animal studies have shown that cigarette smoking induces neutrophil influx to the airspace, increased IL- 8 release and NF- $\kappa B$ activation in the lungs. These effects were abolished by recombinant SOD treatment suggesting cigarette smoke-mediated oxidative stress regulate the molecular events in lung inflammation (Nishikawa et al., 1999). The level of IL-8 was also increased in bronchial epithelial cells of smokers which was associated with airway inflammation (Mio et al., 1997). In fact, cigarette smoke extract treatment of cultured human bronchial epithelium increased the levels of IL-8 and this effect was mimicked by acrolein and acetaldehyde (major components of cigarette smoke). This study suggested that lipid peroxidation products may increase the levels of IL-8 in lungs of smokers which may contribute to lung inflammation (Mio et al., 1997). Similarly Zhang et al. showed that interleukin-6 was induced in mouse spleen and liver in response to sidestream cigarette smoke. The elevated level of IL-6 was blocked by dietary antioxidants (Zhang et al., 2001). In an interesting study conducted by Rusznak and co-workers, bronchial epithelial cells from smokers with COPD showed greater susceptibility to the effects of cigarette smoke, releasing greater levels of IL$1 \beta$ and sICAM-1 compared with smokers without COPD (Rusznak et al., 2000). This study provides some evidence as to why only a proportion of smokers develop COPD. The increased burden of proinflammatory mediators and upregulation of adhesion molecules may be involved in the recruitment and trafficking of inflammatory cells into the airway epithelium seen in smokers and patients with COPD.

Cigarette smoke-mediated lipid peroxidation has been shown to be involved in epithelial remodeling during lung injury. The levels of 4-HNE-adducts are increased in epithelial cells in patients with COPD, which may be of relevance for the understanding of epithelial changes in this disease. In addition to its ability to increase the expression of proinflammatory mediators, 4-HNE has also been shown to induce apoptosis in T cells (Liu et al., 2000) and cause activation of the epidermal growth factor receptor (EGFR) in human epidermoid carcinoma cells, which results in growth inhibition (Liu et al., 1999). Previous studies have shown that cigarette smoke increases mucin production in epithelial cells, a mechanism in which the EGFR was implicated (Takeyama et al., 153). Therefore, it is tempting to speculate that enhanced 4-HNE levels may contribute to mucus cell hyperplasia (induction of muc5ac mRNA), as observed in COPD. In turn, this points/implicates to a potential role for 4-
HNE in the signaling events involved in lung inflammation leading to the development of COPD.

Oxidative stress and 4-HNE have been shown to induce cellular stress responses, such as cell signaling via the MAP kinase pathways, leading to the induction of AP-1-mediated genes (Uchida et al., 1999; Leonarduzzi et al., 2000), for example, the antioxidant $\gamma$-GCS mRNA in alveolar epithelial cells (Liu et al., 2001). $\gamma$-GCS expression is increased in lungs of patients with COPD (Rahman et al., 2000) and in response to cigarette smoke in alveolar epithelial cells (Rahman et al., 1996a). The induction of $\gamma$-GCS may be an important adaptive response of the alveolar epithelium to oxidative stress. Cigarette smoke-mediated oxidative stress has also been implicated in the expression of other protective antioxidant genes. The expression of a number of antioxidant genes was increased in the bronchial epithelial cells in rats exposed to whole cigarette smoke for up to 14 days (Gilks et al., 1998). These include the mRNA of manganese superoxide dismutase (MnSOD), metallothionein (MT) and glutathione peroxidase, suggesting the oxidant/peroxide-mediated upregulation of a battery of antioxidant genes which may be important protective mechanism against the effects of cigarette smoke. Cigarette smoke-induced oxidative stress also causes upregulation of HO-1 and heat shock protein-70 in both human monocytes and endothelial cells as well as in the human premonocytic line U937 cells (Favatier and Polla, 2001; Vayssier-Taussat et al, 2001). An imbalance of an array of redox-regulated antioxidant versus pro-inflammatory genes might be associated with the susceptibility or tolerance to disease (Fig. 4).

\section{Role of ROS and Cigarette Smoke-induced Oxidative Stress in Chromatin Modeling: Role for Histone Acetylation and Deacetylation}

The role of the nucleosome remodeling in the control of gene transcription co-activator and transcription factor access to the target promoter sites of genes is increasingly viewed as an important regulatory mechanism for the transcriptional activation of genes. Levels of histone acetylation have been directly related to the levels of gene transcription. Oxidative stress and proinflammatory mediators have been suggested to influence histone acetylation and phosphorylation by ADPribosylation, via a mechanism dependent on the activation of MAPK pathway (Miyata et al., 2001; Tikoo et al., 2001). Recently, we and other investigators have shown that both $\mathrm{H}_{2} \mathrm{O}_{2}$ and TNF- $\alpha$ (relevant stimuli for cigarette smokemediated inflammatory response) caused an increase in histone acetylation (HAT activity) in alveolar epithelial cells (Ito et al., 2001; Rahman et al., 2001b). The exact mechanism of increased histone acetylation in response to these agents is not clear. It has been reported that oxidants and TNF- $\alpha$ activate MAPK pathways, specifically ERK and JNK, and by activation of these redox-dependent pathways these agents 
may regulate ATF-2 and $\mathrm{CBP}$ co-activators that possess intrinsic HAT activity (Thomson et al., 1999; Kawasaki et al., 2000).

ROS and TNF- $\alpha$ increase the activation of AP- 1 and NF$\kappa \mathrm{B}$, and regulate chromatin remodelling leading to IL- 8 and IL-6 expression in lung cells (Lakshminarayanan et al., 1998; Berghe et al., 1999). Recently Ito and co-workers have shown a role for histone acetylation and deacetylation in IL-1 $\beta$ induced TNF- $\alpha$ release in alveolar macrophages derived from cigarette smokers (Ito et al., 2001). They have also suggested that oxidants may play an important role in the modulation of HDAC and inflammatory cytokine gene transcription. Our preliminary data indicated that cigarette smoke condensate increased the acetylation of histone 4 associated with decreased levels of HDAC 1 and 2 levels in alveolar epithelial cells (Rahman et al., unpublished data). This observation is confirmed in our laboratory in sputum neutrophils where HDAC 1 and 2 expression was associated with NF- $\kappa \mathrm{B}$ activation in COPD patient (Drost et al., unpublished data). We also showed that inhibiting HDACs alone resulted in enhanced activation of AP-1 and NF- $\mathrm{KB}$ and increased histone acetylation culminating in increased IL- 8 release (Rahman $e t$ al., 2001b). This observation corroborated with previous studies showing acetylation of histone proteins is associated with increased binding of the transcription factor AP-1 and NF-KB (Ng et al., 1997; Chen et al., 2001). Thus cigarette smoke-mediated oxidative stress may produce chronic inflammatory response in the airways. IL- 8 release was also augmented when trichostatin A (histone deacetylase inhibitor) was combined with TNF- $\alpha$ or $\mathrm{H}_{2} \mathrm{O}_{2}$, associated with NF- $\kappa$ B binding (Fig. 5). This suggests that inhibition of HDAC allows $\mathrm{NF}-\kappa \mathrm{B}$ to retain in the nucleus and triggers augmented TNF- $\alpha$ or $\mathrm{H}_{2} \mathrm{O}_{2}$-mediated gene transcription. In return, NF- $\kappa \mathrm{B}$ itself is acetylated, which participates in active transcription machinery for prolong transcription (Chen et al., 2001).

It is now known that p65, a component of the NF- $\mathrm{KB}$ transcription factor, has intrinsic HAT activity and transactivation of p65 is independent of nuclear translocation (Ashburner et al., 2001; Ito et al., 2001). It has been recently shown that HDAC1 can interact directly with the p65 subunit of $N F-\kappa B$ to exert its corepressor function in the nucleus. Therefore, NF- $\kappa \mathrm{B}$ interaction with HDAC (1 and 2) proteins may be a further mechanism whereby $\mathrm{NF}-\kappa \mathrm{B}$ can regulate transcription. HDACs may be dissociated/phosphorylated from binding to nuclear p65 by oxidants leading to enhanced p65 acetylation/phosphorylation resulting in IL-8 gene expression. This pathway may not require classic NF- $\kappa \mathrm{B} / \mathrm{I} \mathrm{B}$ kinase pathway.

It has been reported that IL- 8 and IL- 6 release are enhanced by HDAC inhibitors in intestinal epithelial cells and in murine fibrosarcoma L929sA cells (Berghe et al., 1999; Fusunyan et $a l .$, 1999), which also enhance the effect of IL-1 or TNF- $\alpha$ treatments. Similarly, Pender and co-workers have recently demonstrated that HDAC inhibitors (increasing the overall level of acetylation of the histone proteins) enhanced the
A model proposing modulation of histone acetylation and deacetylation in gene transcription

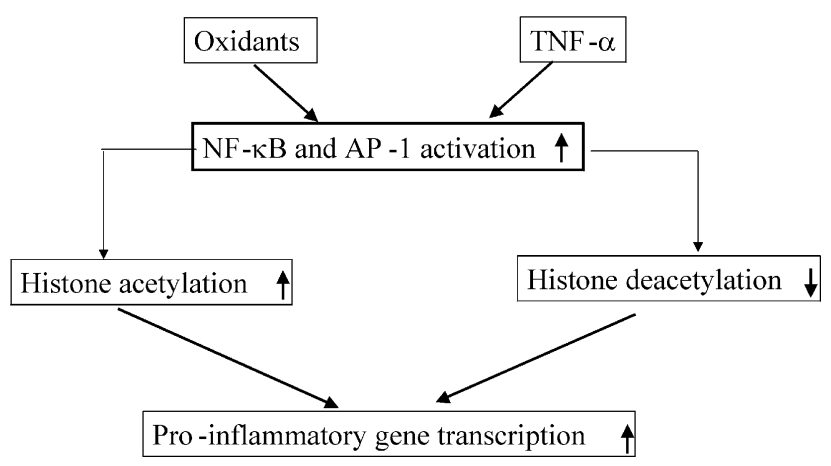

Fig. 5. Schematic diagram showing ROS and TNF- $\alpha$-mediated activation of NF- $\mathrm{KB}$ and AP-1 leading to alteration in histone acetylation/deacetylation and increased pro-inflammatory gene transcription.

levels of stromelysin-1 (matrix metalloproteinase-3) by augmenting histone acetylation by TNF- $\alpha$ or IL-1-stimulated mesenchymal cells (Pender et al., 2000). Shankaranarayanan and co-workers have shown that acetylation of histone 3 and STAT6 by CBP/p300 is associated with 15-lipoxygenase-1 gene expression induced by IL-4 in A549 lung epithelial cells (Shankaranarayanan et al., 2001). Moreover, it is reported that HDAC inhibitors enhance pulmonary cells responsiveness to a subsequent stressor, such as $\mathrm{H}_{2} \mathrm{O}_{2}$ and TNF- $\alpha$, leading to increased transcription factor DNA-binding and enhanced gene expression (Rahman et al., 2001b). This has an implication in inflammatory lung disease states where the HDAC enzyme is inactivated. In these cases, ROS and TNF- $\alpha$ would lead to a further increased inflammatory response from the tissue.

ROS and CSC-mediated inhibition of HDAC-2 levels is also supported by the observations that various proinflammatory mediators such as intercellular adhesion molecule-1 (ICAM-1), IL-8, IL-6, TNF- $\alpha$, IL-1 $\beta$, monocyte chemoattractant protein-1, matrix metalloproteinases and heat shock proteins, which are increased in BAL fluid of smokers, are also induced by inhibition of histone deacetylases. Inhibition of HDAC in tumour cell lines leads to specific chromatin acetylation and alteration of cell cycle proteins, including upregulation of $\mathrm{p} 21^{\text {wafl/cip1 } 1}$ and cyclin E (Sambucetti et al., 1999). Recent data from our laboratory showed that cigarette smoke-mediated inhibition of HDAC may upregulate $\mathrm{p} 21^{\text {wafl/cipl }}$ in alveolar epithelial cells suggesting another role of cigarette smoke in cell cycle regulation (Marwick et al., unpublished data). It has been shown that glucocorticoid suppression of inflammatory genes requires recruitment of HDAC-2 to the transcription activation complex by the glucocorticoid receptor (Ito et al., 2000). This results in deacetylation of histones and a decrease in inflammatory gene transcription. Our preliminary data also suggested that $\mathrm{H}_{2} \mathrm{O}_{2}$ 


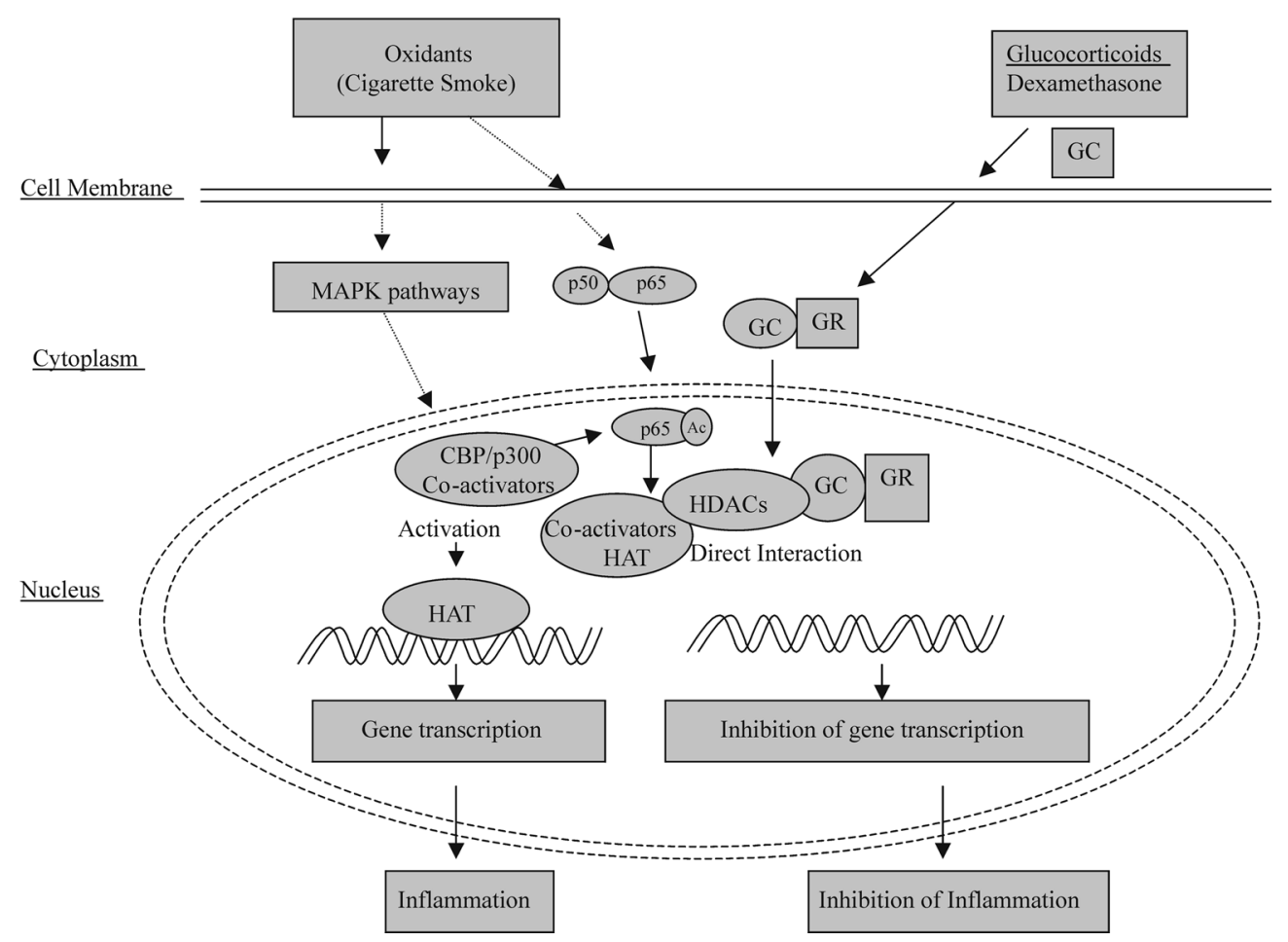

Fig. 6. Model showing the possible mechanism of histone acetylation by oxidative stress and its repression by corticosteroids (GCs) leading to inhibition of gene transcription. MAP kinase signaling pathways may be activated by oxidative stress leading to histone acetylation. Direct interaction between co-activators (HAT), histone deacetylase and the glucocorticoid receptor (GR) may result in repression of the expression of pro-inflammatory genes. HDAC forms a bridge with HAT to inhibit gene transcription. However, when the HDAC is inhibited by oxidants or the NF- $\mathrm{KB}$ subunit p65 is acetylated, steroids may not be able to recruit HDACs into the transcriptional complex to inhibit pro-inflammatory gene expression.

and TNF- $\alpha$-mediated induction of IL-8 was partially blocked by dexamethasone when the HDAC activity as inhibited by TSA in alveolar epithelial cells (Rahman et al., unpublished data).

The reduced level of HDAC-2 was associated with increased proinflammatory response and reduced responsiveness to glucocorticoids in alveolar macrophages obtained from smokers (Ito et al., 2001). The cigarette smoke/ oxidant-mediated reduction in HDAC-2 levels in alveolar epithelial cells will not only increase inflammatory gene expression but will also cause a decrease in glucocorticoid function (Fig. 6). This may be one of the potential reasons for the failure of glucocorticoids to function effectively in reducing inflammation in COPD. The signaling mechanisms involved in the cigarette smoke-mediated chromatin remodeling and glucocorticoid insensitivity are currently unknown. It may be possible that cigarette smoke-mediated formation of potential aldehydes/ acetaldehydes is responsible for oxidation/nitrosylation/ phosphorylation of HDACs during inflammation. Nevertheless, oxidative stress results in an imbalance between histone acetylation and deacetylation, which may account for the enhanced expression of inflammatory mediators leading to amplification of lung inflammation. This may serve as a potential mechanism for therapeutic intervention to ameliorate the chronic inflammatory response which occurs in the development of smoking-induced chronic inflammatory lung disease such as COPD.

\section{Conclusions}

ROS may be critical to the inflammatory response to cigarette smoke/environmental oxidants, through the upregulation of redox-sensitive transcription factors, alteration in histone acetylation/deacetylation and hence pro-inflammatory gene expression; but is also involved in the protective mechanisms against the effects of cigarette smoke by the induction of antioxidant genes. Further understanding of the effects and roles of ROS in basic cellular functions as amplification of pro-inflammatory and immunological responses, signalling pathways, activation of transcription factors, chromatin remodeling (histone acetylation and deacetylation) and gene expression will provide important information regarding basic pathological processes contributing to chronic lung diseases such as COPD. Identification of genes that predispose to the development of chronic lung diseases may identify novel therapeutic targets. 
The effective wide spectrum antioxidant therapy that has good bioavailability and potency/long lasting action is urgently needed to control the underlying oxidative and inflammatory processes that occur in the pathogenesis of chronic inflammatory lung diseases. Therefore, study of the protective role of antioxidant compounds on inhibition of the inflammatory response and correcting the fundamental oxidant/antioxidant imbalance in patients with lung diseases are an important area of further research. Understanding of the molecular mechanisms of antioxidants on ROS-mediated cell signaling pathways would provide information for development of novel antioxidant therapeutic agents to prevent the progression of chronic lung diseases such as COPD. The proof of concept for the role of oxidative stress in the pathogenesis of chronic lung diseases will come from clinical studies on the effectiveness of antioxidant therapy.

\section{References}

Aaron, S. D., Angel, J. B., Lunau, M., Wright, K., Fex, C., Le Saux, N. and Dales, R. E. (2001). Granulocyte inflammatory markers and airway infection during acute exacerbation of chronic obstructive pulmonary disease. Am. J. Respir. Crit. Care Med. 163, 349-355.

Adler, V., Yin, Z., Tew, K. D. and Ronai, Z. (1999) Role of redox potential and reactive oxygen species in stress signaling. Oncogene 18, 6104-6111.

American Thoracic Society Standards for the diagnosis and care of patients with chronic obstructive pulmonary disease. (1995) Am. J. Respir. Crit. Care. Med. 152, S77-S120.

Asami, S., Hirano, T., Yamaguchi, R., Tomioka, Y., Itoh, H. and Kasai, H. (1996) Increase of a type of oxidative DNA damage, 8-hydroxyguanine, and its repair activity in human leukocytes by cigarette smoking. Cancer Res. 56, 2546-2549.

Ashburner, B. P., Westerheide, S. D. and Baldwin, A. S. Jr. (2001) The p65 (RelA) subunit of NF-kappaB interacts with the histone deacetylase (HDAC) corepressors HDAC1 and HDAC2 to negatively regulate gene expression. Mol. Cell Biol. 21, 7065-7077.

Berghe, W. V., Bosscher, K. D., Boone, E., Plaisance, S. and Haegeman, G. (1999) The nuclear factor- $\kappa B$ engages CBP/ p300 and histone acetyltransferase activity for transcriptional activation of the interleukin-6 gene promoter. J. Biol. Chem. 274, 32091-32098.

Bermudez, E., Stone, K., Carter, K. M. and Pryor, W. A. (1994) Environmental tobacco smoke is just as damaging to DNA as mainstream smoke. Environ. Health Perspect. 102, 870-874.

British Thoracic Society Guidelines for the Management of Chronic Obstructive Pulmonary Disease. (1997) Thorax 52, S1S28.

Britton, J. R., Pavord, I. D., Richards, K. A., Knox, A. J., Wisniewski, A. F., Lewis, S. A., Tattersfield, A. E. and Weiss, S. T. (1995). Dietary antioxidant vitamin intake and lung function in the general population. Am. J. Respir. Crit. Care Med. 151, 1383-1387.

Bohm, L., Schneeweiss, F. A., Sharan, R. N. and Feinendegen, L. E. (1997). Influence of histone acetylation on the modification of cytoplasmic and nuclear proteins by ADP-ribosylation in response to free radicals. Biochim. Biophys. Acta 1334, 149154.

Borish, E. T., Pryor, W. A., Venugopal, S., Deutsch, W. A. (1987) DNA synthesis is blocked by cigarette tar-induces DNA singlestrand breaks. Carcinogenesis 8, 1517-1520.

Bosken, C. H., Hards, J., Gatter, K. and Hogg, J. C. (1992) Characterization of the inflammatory reaction in the peripheral airways of cigarette smokers using immunocytochemistry. Am. Rev. Respir. Dis. 145, 911-917.

Brown, D. M., Drost, E., Donaldson, K. and MacNee, W. (1995) Deformability and CD11/CD18 expression of sequestered neutrophils in normal and inflamed lungs. Am. J. Respir. Cell. Mol. Biol. 13, 531-539.

Cebulska-Wasilewska, A., Wierzewska, A., Nizankowska, E., Graca, B., Hughes, J. A. and Anderson, D. (1999) Cytogenetic damage and ras p21 oncoprotein levels from patients with chronic obstructive pulmonary disease (COPD), untreated lung cancer and healthy controls. Mutat. Res. 431, 123-131.

Chan-Yeung, M., Abboud, R., Dybuncio, A. and Vedal, S. (1988) Peripheral leucocyte count and longitudinal decline in lung function. Thorax 43, 426-468.

Chang, W. C., Lee, Y. C., Liu, C. L., Hsu, J. D., Wang, H. C., Chen, C. C. and Wang, C. J. (2001) Increased expression of iNOS and c-fos via regulation of protein tyrosine phosphorylation and MEK1/ERK2 proteins in terminal bronchiole lesions in the lungs of rats exposed to cigarette smoke. Arch. Toxicol. 75, 28-35.

Chen, L. F., Fischle, W., Verdin, E. and Greene W. C. (2001) Duration of nuclear NF- $\kappa B$ action regulated by reversible acetylation. Science 293, 1653-1657.

Church, T. and Pryor, W. A. (1985) Free radical chemistry of cigarette smoke and its toxicological implications. Environ. Health Perspect. 64, 111-126.

Davie, J. R. and Spencer, V. A. (2001) Signal transduction pathways and the modification of chromatin structure. Progress in Nuc. Acid Res Mol. Biol. 65, 299-340.

Favatier, F. and Polla, B. S. (2001) Tobacco-smoke-inducible human haem oxygenase-1 gene expression: role of distinct transcription factors and reactive oxygen intermediates. Biochem. J. 353, 475-482.

Finnin, M. S., Donigian, J. R., Cohen, A., Richon, V. M,. Rifkind, R. A., Marks, P. A., Breslow, R. and Pavletich, N. P. (1999) Structures of a histone deacetylase homologue bound to the TSA and SAHA inhibitors. Nature 401, 188-193.

Fiorini, G., Crespi, S., Rinaldi, M., Oberti, E., Vigorelli, R. and Palmieri, G. (2000) Serum ECP and MPO are increased during exacerbations of chronic bronchitis with airway obstruction. Biomed. Pharmacother. 54, 274-278.

Freed, B. M., Ouyang, Y. and McCue, J. M. (2001) Mechanisms of altered transcription by cigarette smoke. Toxicol. Sci. 59, 12.

Fusunyan, R. D, Quinn, J. J,. Fujimoto, M., MacDermott, R. P. and Sanderson, I. R. (1999) Butyrate switches the pattern of chemokine secretion by intestinal epithelial cells through histone acetylation. Mol. Med. 5, 631-640.

Gebel, S. and Muller, T. (2001) The activity of NF-kappa B in Swiss 3 T3 cells exposed to aqueous extracts of cigarette smoke is dependent on thioredoxin. Toxicol. Sci. 59, 75-81.

Gilks, C. B., Price, K., Wright, J. L. and Churg, A. (1998) 
Antioxidant gene expression in rat lung after exposure to cigarette smoke. Am. J. Path. 152, 269-278.

Gompertz, S., Bayley, D. L., Hill, S. L., Stockley, R. A. (2001) Relationship between airway inflammation and the frequency of exacerbations in patients with smoking related COPD. Thorax 56 36-41

Imhof, A. and Wolffe, A. P. (1998) Transcription: gene control by targeted histone acetylation. Curr. Biol. 8, R422-R424.

Ito, K., Barnes, P. J. and Adcock, I. M. (2000) Glucocorticoid receptor recruitment of histone deacetylase 2 inhibits interleukin-1beta-induced histone $\mathrm{H} 4$ acetylation on lysines 8 and 12. Mol.Cell. Biol. 20, 6891-6903.

Ito, K., Lim, G., Caramori, G., Chung, K. F,. Barnes, P. J. and Adcock, I. M. (2001) Cigarette smoking reduces histone deacetylase 2 expression, enhances cytokine expression, and inhibits glucocorticoid actions in alveolar macrophages. FASEB J. 15, 1110-1112.

Izzotti, A., Balansky, R., Scatolini, L., Rovida, A. and Flora, S. D. (1995) Inhibition of $\mathrm{N}$-acetylcysteine of carcinogen-DNA adducts in the tracheal epithelium of rats exposed to cigarette smoke. Carcinogenesis 16, 669-672.

Kawasaki, H., Schiltz, L., Chiu, R., Itakura, K., Taira, K., Nakatani, Y. and Yokoyama, K. K. (2000) ATF-2 has instrinsic histone acetyltransferase activity which is modulated by phosphorylation. Nature 405, 195-200.

Lakshminarayanan, V., Drab-Weiss, E. A. and Roebuck, K. A. (1998) $\mathrm{H}_{2} \mathrm{O}_{2}$ and TNF induce differential binding of the redoxresponsive transcription factor $\mathrm{AP}-1$ and $\mathrm{NF}-\mathrm{kB}$ to the imterleukin-8 promoter in endothelial and epithelial cells. $J$. Biol. Chem. 273, 32670-32678.

Leanderson, P. and Tagesson, C. (1994) Cigarette tar promotes neutrophil-induced DNA damage in culture lung cells. Environ. Res. 64, 103-111.

Leonarduzzi, G., Arkan, M. C., Basaga, H., Chiarpotto, E., Sevanian, A. and Poli, G. (2000) Lipid oxidation products in cell signaling. Free Radic. Biol. Med. 28, 1760-1768.

Liu, R. M., Borok, Z. and Forman, H. J. (2001) 4-Hydroxy-2nonenal increases $\beta$-glutamylcysteine synthetase gene expression in alveolar epithelial cells. Am. J. Respir. Cell Mol. Biol. 24, 499-505.

Liu, W., Akhand, A. A., Kato, M., Yokoyama, I., Miyata, T., Kurokawaka, K., Uchida, K. and Nakashima, I. (1999) 4Hydroxynonenal triggers an epidermal growth factor receptorlinked signal pathway for growth inhibition. J. Cell Sci. 112, 2409-2417.

Liu, W, Kato M, Akhand AA, Hayakawa A, Suzuki H, Miyata T, Kurokawa K, Hotta Y, Ishikawa N, Nakashima I. (2000). 4Hydroxynonenal induces a cellular redox status-related activation of the caspase cascade for apoptotic cell death. $J$. Cell Sci. 113 635-641.

MacNee, W. and Rahman, I. (1999) Oxidants and antioxidant in COPD: Therapeutic targets. Am. J. Respir. Crit. Care Med. 160, S1-S8.

Mio, T., Romberger, D. J., Thompson, A. B., Robbins, R. A., Heires, A. and Rennard, S. I. (1997) Cigarette smoke induces interleukin-8 release from human bronchial epithelial cells. Am. J. Respir. Crit. Care Med. 155, 1770-1776.

Miyata, Y., Towatari, M., Maeda, T., Ozawa, Y. and Saito, H. (2001) Histone acetylation induces by granulocyte colonystimulating factor in a MAP kinase-dependent manner.
Biochem. Biophys. Res. Commun. 283, 655-660.

Mochida-Nishimura, K., Surewicz, K., Cross, J. V., Hejal, R., Templeton, D., Rich, E. A. and Toossi, Z. (2001) Differential activation of MAP kinase signaling pathways and nuclear factor-kappa B in bronchoalveolar cells of smokers and nonsmokers. Mol. Med. 7, 177-185.

Montuschi, P., Collins, J. V., Ciabattoni, G., Lazzeri, N., Corradi, M., Kharitonov, S. and Barnes, A. (2000) Exhaled 8isoprostane as an in vivo biomarker of lung oxidative stress in patients with COPD and healthy smokers. Am. J. Respir. Crit. Care Med. 162, 1175-7.

Morrison, D., Rahman, I., Lannan, S. and MacNee, W. (1999) Epithelial permeability, inflammation and oxidant stress in the airspaces of smokers. Am. J. Respir. Crit. Care Med. 159, 473479.

Morrow, J. D. and Roberts, L. J. (1997) The isoprostanes: unique bioactive products of lipid peroxidation. Prog. Lipid Res. 36, 121.

Muller, T. (1995) Expression of c-fos in quiescent Swiss 3 T3 cells exposed to aqueous cigarette smoke fractions. Cancer Res. 55, 1927-1932

Muller, T. and Gebel, S. (1998) The cellular stress response induced by aqueous extracts of cigarette smoke is critically dependent on the intracellular glutathione concentration. Carcinogenesis 19, 797-801.

Muller, T., Haussmann, H. J. and Schepers, G. (1997) Evidence for peroxynitrite as an oxidative stress-inducing compound of aqueous cigarette smoke fractions. Carcinogenesis 18, 295-301.

Nishikawa, M,. Nobumasa, K., Ito, T., Kudi, M., Kaneeko, T., Suzuki, M., Udaka, N., Ikeda, H. and Okubo, T. (1999) Superoxide mediates cigarette smoke-induced infiltration of neutrophils into the airways through nuclear factor- $\mathrm{KB}$ activation and IL-8 mRNA expression in guinea pigs in vivo. Am. J. Respir. Cell Mol. Biol. 20, 189-198.

Ng, K. W., Ridgway, P., Cohen, D. R. and Tremethick, D. J. (1997) The binding of a Fos/Jun heterodimer can completely disrupt the structure of a nucleosome. EMBO J. 16, 2072-2085.

Noguera, A,. Busquets, X., Sauleda, J., Villaverde, J. M,. MacNee, W. and Agusti, A. G. (1998) Expression of adhesion molecules and G-proteins in circulating neutrophils in COPD. Am. J. Respir. Crit. Care Med. 158, 1664-1668.

Nowak, D., Kasielski, M., Antczak, A., Pietras, T., Bialasiewicz, P. (1999) Increased content of thiobarbiturate reactive acid substances in hydrogen peroxide in the expired breath condensate of patients with stable chronic obstructive pulmonary disease: no significant effect of cigarette smoking. Resp. Med. 93, 389-396.

Ogryzko, V. V., Schiltz, R. L., Russanova, V., Howard, B. H. and Nakatani, Y. (1996). The transcriptional coactivators p300 and CBP are histone acetyltransferases. Cell 87, 953-959.

Paredi, P., Kharitonov, S. A., Leak, D., Ward, S., Cramer, D. and Barnes, P. J. (2000) Exhaled ethane, a marker of lipid peroxidation, is elevated in Chronic Obstructivel Pulmonary Disease. Am. J. Respir. Crit. Care Med. 161, 369-373.

Parola, M., Bellomo, G., Robino, G., Barrera, G. and Dianzani, M. U. (1999) 4-Hydroxynonenal as a biological signal: molecular basis and pathophysiological implications. Antioxid. Redox Signalling 1, 255-84.

Pender, S. L. F., Quinn, J. J, Sanderson, I. R. and MacDonald, T. T. (2000) Butyrate upregulates stromelysin-1 production by 
intestinal mesenchymal cells. Am. J. Physiol. Gastrointest. Liver Physiol. 279, G918-G924.

Perera, F. P., Santella, R. M., Brenner, D., M. Poirier, C., Munshi, A. A., Finschman, H. K. and Ryzin, J. V. (1987) DNA adducts, protein adducts, and sister chromatid exchange in cigarette smokers and nonsmokers. J. Natl. Cancer Inst. 79, 449-456.

Pham, A. and Sauer, F. (2000) Ubiquitin-activating/conjugating activity of TAFII250, a mediator of activation of gene expression in Drosophila. Science 289, 2357-2360.

Philips, D. H., Hewer, A., Martin, C. N., Garner, R. C. and King, M. M. (1998) Correlation of DNA adduct levels in human lung with cigarette smoking. Nature 336, 790-792.

Postma, D. S., Renkema, T. E. J., Noordhoek, J. A., Faber, H., Sluiter, H. J. and Kauffman, H. (1988) Association between nonspecific bronchial hyperreactivity and superoxide anion production by polymorphonuclear leukocytes in chronic airflow obstruction. Am. Rev. Respir. Dis. 137, 57-61.

Pryor, W. A. (1992) Biological effects of cigarette smoke, wood smoke, and the smoke from plastics: the use of electron spin resonance. Free Radic. Biol. Med. 13, 659-676.

Pryor, W. A. and Stone, K. (1993) Oxidants in cigarette smoke: radicals, hydrogen peroxides, peroxynitrate, and peroxynitrite. Annals. N. Y. Acad. Sci. 686, 12-28.

Rahman, I., Crowther, A., de Boer, W. I., van Schadewijk, W. A. A. M., Hiemstra, P. S., Stolk, J. and MacNee, W. (2001a) 4Hydroxy-2-nonenal, a specific lipid peroxidation product is elevated in lungs of patients with chronic obstructive pulmonary disease (COPD). Am. J. Respir. Crit. Care Med. 163, A31.

Rahman, I., Gilmour, P. S., Jimenez, L. A. and MacNee, W. (2001b) Oxidative Stress Induces Histone Acetylation In Alveolar Epithelial Cells (A549). Am. J. Respir. Crit. Care Med. 163, A61.

Rahman, I., Morrison, D. Donaldson, K. and MacNee, W. (1996b) Systemic oxidative stress in asthma, COPD, and smokers. Am. J. Respir. Crit. Care Med. 154, 1055-1060.

Rahman, I. and MacNee, W. (1996) Role of oxidants/antioxidants in smoking-induced airways diseases. Free Rad. Biol. Med. 21, 669-681.

Rahman, I. and MacNee, W. (1998) Role of transcription factors in inflammatory lung diseases. Thorax 53, 601-612.

Rahman, I. and MacNee, W. (1999) Lung glutathione and oxidative stress: Implications in cigarette smoke-induced airways disease. Am. J. Physiol. 277, L1067-L1088.

Rahman, I. and MacNee, W. (2000a) Regulation of redox glutathione levels and gene transcription in lung inflammation: therapeutic approaches. Free Radic. Biol. Med. 28, 1405-1420.

Rahman, I. and MacNee, W. (2000b) Oxidative stress and regulation of glutathione synthesis in lung inflammation. Eur. Respir. J. 16, 534-554.

Rahman, I., Lawson, M. F., Smith, C. A. D. Harrison, D. J. and MacNee, W. (1996a) Induction of $\gamma$-glutamylcysteine synthetase by cigarette smoke is associated with AP-1 in human alveolar epithelial cells. FEBS Lett. 396, 21-25.

Rahman, I., Skwarska, E. and MacNee, W. (1997) Attenuation of oxidant/antioxidant imbalance during treatment of exacerbations of chronic obstructive pulmonary disease. Thorax 52, 565-568.

Rahman, I., Mulier, B., Gilmour, P. S., Watchorn, T., Donaldson, K,. Jefferey, P. K. and MacNee, W. (2001c) Oxidant-mediated lung epithelial cell tolerance: the role of intracellular glutathione and nuclear factor-kappaB. Biochem. Pharmacol. 62, 787-794.

Rahman, I., Van Schadewijk, A. A. M., Hiemstra, P. S., Stolk, J., Van Krieken, J. H. J. M., MacNee, W. and De Boer, W. I. (2000) Localisation of $\gamma$-glutamylcysteine synthetase messenger RNA expression in lungs of smokers and patients with chronic obstructive pulmonary disease. Free Radic. Biol. Med. 28, 920925.

Richards, G. A., Theron, A. J., van der Merwe, C. A. and Anderson, R. (1989) Spirometric abnormalities in young smokers correlate with increased chemiluminescence responses of activated blood phagocytes. Am. Rev. Respir. Dis. 139, 181187.

Rochelle, L. G., Fischer, B. M. and Adler, K. B. (1998) Concurrent production of reactive oxygen and nitrogen species by airway epithelial cells in vitro. Free Radic. Biol. Med. 24, 863-868.

Rusznak, C., Mills, P. R., Devalia, J. L., Sapsford, R. J., Davies, R. J. and Lozewicz, S. (2000) Effect of cigarette smoke on the permeability and IL-1 $\beta$ and sICAM-1 release from cultured human bronchial epithelial cells of never-smokers, smokers, and patients with chronic obstructive pulmonary disease. Am. J. Respir. Cell Mol. Biol. 23, 530-536.

Sambucetti, L. C., Fischer, D. D., Zabludoff, S., Kwon, P. O., Chamberlin, H., Trogani, N., Xu, H. and Cohen, D. (1999) Histone deacetylase inhibition selectively alters the activity and expression of cell cycle proteins leading to specific chromatin acetylation and antiproliferative effects. J. Biol. Chem. 274, 34940-34947.

Shankaranarayanan, P., Chaitidis, P., Kuhn, H. and Nigam, S. (2001) Acetylation by histone acetyl transferases CBP/p300 of STAT6 is required for transcriptional activation of the 15lipoxygenase-1 gene. J. Biol. Chem. 276, 42753-42760.

Takeyama, K., Jung, B., Shim, J. J., Burgel, P. R., Dao-Pick, T., Ueki, I. F., Protin, U., Kroschel, P. and Nadel, J. A. (2001) Activation of epidermal growth factor receptors is responsible for mucin synthesis induced by cigarette smoke. Am. J. Physiol. Lung Cell Mol. Physiol. 280, L165-L172.

Thannickal, V. J., Fanburg, B. L. (2000) Reactive oxygen species in cell signaling. Am. J. Physiol. Lung Cell Mol. Physiol. 279, L1005-L1028.

Thompson, A. B., Bohling, T., Heires, A., Linder, J. and Rennard, S. I. (1991) Lower respiratory tract iron burden is increased in association with cigarette smoking. J. Lab. Clin. Med. 117, 494-499.

Thomson, S., Mahadevan, L. C., Clayton, A. L. (1999) MAP kinase-mediated signaling to nucleosomes and immediate-early gene induction. Semin. Cell Dev. Biol. 10, 205-214.

Tikoo, K., Lau, S. S. and Monks, T. J. (2001) Histone H3 phosphorylation is coupled to poly-(ADP-ribosylation) during reactive oxygen species-induces cell death in renal proximal tubular epithelial cells. Mol. Pharmacol. 60, 394-402.

Uchida, K., Shiraishi, M., Naito, Y., Torii, N., Nakamura, Y. and Osawa, T. (1999). Activation of stress signaling pathways by the end product of lipid peroxidation. J. Biol. Chem. 274, 2234-2242.

Vayssier-Taussat, M., Camilli, T., Aron, Y,. Meplan, C., Hainaut, P., Polla, B. S. and Weksler, B. (2001) Effects of tobacco smoke and benzo[a]pyrene on human endothelial cell and 
monocyte stress responses. Am. J. Physiol. Heart Circ. Physiol. 280, H1293-H1300.

Wu, C. (1997) Chromatin remodeling and the control of gene expression. J. Biol. Chem. 272, 28171-28174.

Wyatt, T. A., Heires, A. J., Sanderson, S. D. and Floreani, A. A. (1999) Protein kinase C activation is required for cigarette smoke-enhanced C5 $\alpha$-mediated release of interleukin- 8 in human bronchial epithelial cells. Am. J. Respir. Cell Mol. Biol.
21, 283-288.

Zang, L. Y., Stone, K. and Pryor, W. A. (1995) Detection of free radicals in aqueous extracts of cigarette tar by electron spin resonance. Free Radic. Biol. Med. 19, 161-167.

Zhang, J., Jiang, S. and Watson, R. R. (2001) Antioxidant supplementation prevents oxidation and inflammatory responses induced by sidestream cigarette smoke in old mice. Environ. Health Perspect. 109, 1007-1009. 